\title{
Effects of red to far-red light ratio on growth and photosynthetic characteristics of tomato seedlings under calcium nitrate stress
}

\author{
X.T. ZHOU ${ }^{\dagger,+}$, Z.L. LI ${ }^{\dagger}$, J.J. HE ${ }^{\dagger}$, X.Y. WANG, Q.L. LIU, J. HUANG, Y.D. XIE, and Z.Q. HE \\ College of Horticulture, Sichuan Agricultural University, 611130 Chengdu, China
}

\begin{abstract}
Secondary soil salinization causes plant stress, which can be relieved by different ratios of red to far-red light (R:FR). Our study aimed to elucidate the role of low R:FR ratios treatments on photosynthesis and growth of tomato seedlings in salinized soils. Tomato seedlings were treated under three R:FR ratios and calcium nitrate was applied simultaneously. The results showed that the treatments under low R:FR ratios stimulated growth parameters of tomato seedlings under calcium nitrate stress, the best impact being achieved at the R:FR ratio of 0.7 in this experiment. Low R:FR ratios treatments increased proline content as well as PSII maximum efficiency, actual electron transport operating efficiency, and photochemical quenching of tomato seedlings under calcium nitrate stress but decreased the value of nonphotochemical quenching. Moreover, low R:FR ratios treatments promoted net photosynthetic rate and increased the expression of a Rubisco gene. In conclusion, low R:FR ratios treatments could improve the salt resistance of greenhouse tomato plants.
\end{abstract}

Keywords: calcium nitrate stress; chlorophyll fluorescence; photosynthesis; red to far-red light ratio; salt stress; tomato.

\section{Introduction}

Recently, intensive management practices for growing vegetables subjected to protected horticulture have increased the degree of secondary soil salinization. Excessive tillage, large quantities of fertilizers, and lack of rainwater have aggravated the degree of soil salinization occurring during this process (Rozema and Flowers 2008). Salinization can cause soil compaction and fertility declines, which impedes the yields and quality of plants (Ors et al. 2021). Furthermore, the excessive accumulation of salt ions primarily causes ion toxicity, osmotic stress, and

\section{Highlights}

- LED was used to set the light environment at different R:FR ratio treatments

- The photosynthesis capacity of tomato was improved under a low R:FR ratio treatment

- Salt tolerance of tomato seedlings improved under a low R:FR ratio treatment
Received 14 May 2021

Accepted 1 November 2021

Published online 23 November 2021

${ }^{+}$Corresponding authors

e-mail: zhouxiaoting6412@hotmail.com (X.T. Zhou) 546892485@qq.com (Z.Q.He)

Abbreviations: $C_{\mathrm{i}}$ - intercellular $\mathrm{CO}_{2}$ concentration; D - antenna heat dissipation; DM - dry mass; $E$ - transpiration rate; $\mathrm{Ex}$ - excess energy in the reaction centre during the photochemical reaction; $\mathrm{F}_{0}$ - minimal fluorescence from the dark-adapted leaf; $\mathrm{F}_{0}{ }^{\prime}$ - minimal fluorescence from the light-adapted leaf; $\mathrm{FM}$ - fresh mass; $\mathrm{F}_{\mathrm{m}}$ - maximal fluorescence from the dark-adapted leaf; $\mathrm{F}_{\mathrm{m}}{ }^{\prime}$ - maximal fluorescence from the light-adapted leaf; FR - far-red light; $F_{s}$ - steady-state fluorescence yield; $F_{v} / F_{m}-$ maximum quantum efficiency of PSII photochemistry; $\mathrm{F}_{\mathrm{v}}{ }^{\prime} / \mathrm{F}_{\mathrm{m}}{ }^{\prime}$ - PSII maximum efficiency; $g_{\mathrm{s}}$ - stomatal conductance; LED - light-emitting diode; $\mathrm{NPQ}$ - nonphotochemical quenching; $\mathrm{P}$ - reduced PSII photochemistry; $P_{\mathrm{N}}$ - net photosynthetic rate; $\mathrm{q}_{\mathrm{P}}$ - photochemical quenching; $\mathrm{R}$ - red light; R:FR - red to far-red light ratio; $\Phi_{\mathrm{PSII}}$ - actual electron transport operating efficiency.

Acknowledgements: This work was supported financially through the Study on Vegetable Science of Farmland System in Qinghai-Tibet Plateau (063-2022219001), the double support scheme of Sichuan Agricultural University (035-2021993323), and college student innovation training program of Sichuan Agricultural University (040-2021998128).

These authors contributed equally to this work.

Conflict of interest: The authors declare that they have no conflict of interest. 
physiological metabolic disorders, affecting components in photosynthetic organs, such as enzymes, thylakoid membrane proteins, and membrane lipids (Lakshmi et al. 1996, Misra et al. 1997). In the greenhouse soil in China, a study reported that $\mathrm{Ca}^{2+}$ was the primary cation, whereas $\mathrm{NO}_{3}^{-}$was the primary anion (Yuan et al. 2012), which further establishes the effect of protected horticulture on soils.

Plants sense changes in light quality through several light signal receptors (phytochrome, cryptochrome, UV receptor uvr8, etc.). These signals are then transmitted to various downstream light signal transduction factors. Among the light receptors, phytochrome is a red/far-red light-sensing plant pigment protein that plays an important role in adaptive responses of seed germination, flowering, developmental transformation, phototaxis, and shade response (Quail 2002). Moreover, it carries corresponding signals to influence gene expression (Craig and Runkle 2013, Possart et al. 2017). Phytochrome can exist in two configurations - red light absorption and far-red light absorption. Driven by red (R) and far-red (FR) light, the two configurations can be interconverted (Franklin and Quail 2010). The ratio of red to far-red light (R:FR) is an important parameter that affects phytochromes ( $\mathrm{Li}$ et al. 2011). Both phytochromes and their interacting transcription factors can therefore constitute a functional signal-regulation and transduction system in plants, being involved in plant regulation of pathogenic microorganisms (Wang et al. 2010) and pests (Yang et al. 2015). Moreover, phytochromes are involved in regulating plant resistance to abiotic stresses, such as shade response (Martínez-García et al. 2014), drought (Boggs et al. 2010), and temperature stress (Kim et al. 2002, Wang et al. 2018).

By sensing environmental changes in the R:FR ratio, plants can detect changes in shade state, seasonal light cycle, and temperature changes (Hendricks and Borthwick 1967, Hertel et al. 2011). Moreover, low R:FR ratios are involved in abiotic stress tolerance. Research by Arico et al. (2019) found that $p h y B$ was crucial to the heat tolerance of Arabidopsis thaliana plants under low R:FR ratios treatments. In the same research, reduced $p h y B$ were found to decrease the transcriptome levels of several fatty acid desaturases and that of unsaturated fatty acids. Furthermore, Ahres et al. (2020) found that reduction in $\mathrm{R}:$ FR ratios positively affected the frost resistance of barley. Alternatively, phyB mutants were unable to alleviate the growth inhibition caused by salt stress in tomato seedlings, whereas this inhibition was prevalent in the wild type (Cao et al. 2018). According to these studies, phytochromes influenced the regulation of hormone production in plants exposed to varying $\mathrm{R}: \mathrm{FR}$ ratios, including their salt tolerance (Franklin and Quail 2010, Fahad et al. 2015). Moreover, phytochromes can regulate the expression of several proteins that mediate resistance to salt stress (Indorf et al. 2007). Based on these findings, salt tolerance and photosensitivity were established to be interconnected via complicated signalling networks. Hence, under low $\mathrm{R}: \mathrm{FR}$ ratios, plants can readjust and balance growth to enhance salt resistance. Nevertheless, the mechanism by which this occurs needs to be explored further.

Tomato (Solanum lycopersicum L.) is the most widely grown vegetable globally (Bergougnoux 2014) and is among the most extensively grown vegetables in protected horticulture. In this study, the effects of different R:FR ratios treatments on growth, salinity, photosynthesis, and chlorophyll fluorescence were investigated in tomato seedlings under saline stress conditions. By describing the interaction between R:FR ratios and salinity, we should be able to provide more evidence for the reason behind low R:FR ratios observed during tomato tolerance to salinization.

\section{Materials and methods}

Plant materials and treatment: As plant material, the tomato variety 'Jinpeng No. 1' was used. The experiments were carried out at Sichuan Agricultural University from May to December 2020. Seeds were sterilized, imbibed, and germinated and the obtained seedlings were grown in a growth chamber (Sichuan Agricultural University, Chengdu, China), at $26 \pm 1^{\circ} \mathrm{C}$ during the day and $18 \pm 1^{\circ} \mathrm{C}$ during the night, under light/dark cycle of $16 / 8 \mathrm{~h}$, relative humidity of $70 \%$, and light intensity of $200 \pm$ $25 \mu$ mol(photon) $\mathrm{m}^{-2} \mathrm{~s}^{-1}$. After the development of the first three true leaves, healthy seedlings in the same growth stage were transplanted into a matrix culture bowl $(15 \times 13 \mathrm{~cm})$ and grown in a greenhouse. The cultivation substrate contained peat, vermiculite, and perlite in a ratio of $3: 1: 1$. The seedlings were irrigated with $1 / 2$ Hoagland nutrient solution once every three days. Six different treatments were set in this experiment (see the text table below).

The treatment period with the light of different R:FR ratios was $16 \mathrm{~h}(8: 00-24: 00 \mathrm{~h})$ per day for both treatment and control groups. However, the R:FR ratio of the white LED light used in the growth chamber was about 4.2. For the R:FR ratio calculation, the ratio of the total red light radiation intensity $(655-665 \mathrm{~nm})$ to the total far-red light radiation intensity $(725-735 \mathrm{~nm})$ was used. Then, PPFD was measured using the $O H S P-350 P$ spectrum analyzer

\begin{tabular}{llll}
\hline Treatment & Light source & Nutrient solution \\
\hline S & salt stress & white LED (R:FR = 4.2) & $160 \mathrm{mmol} \mathrm{L}^{-1} \mathrm{Ca}\left(\mathrm{NO}_{3}\right)_{2}$ \\
L1 & normal nutrient solution + 1.0 R:FR & white LED + far-red LED (R:FR ratio = 1.0) & normal nutrient solution \\
SL1 & salt stress + 1.0 R:FR & white LED + far-red LED (R:FR ratio $=1.0)$ & $160 \mathrm{mmol} \mathrm{L}^{-1} \mathrm{Ca}\left(\mathrm{NO}_{3}\right)_{2}$ \\
L2 & normal nutrient solution + 0.7 R:FR & white LED + far-red LED (R:FR ratio = 0.7) & normal nutrient solution \\
SL2 & salt stress + 0.7 R:FR & white LED + far-red LED (R:FR ratio $=0.7)$ & 160 mmol L $\left.\mathrm{La}^{-1} \mathrm{Ca}_{3}\right)_{2}$ \\
CK & control & white LED (R:FR = 4.2) & normal nutrient solution \\
\hline
\end{tabular}


(Hopoocolor, China), whereas low R:FR treatment was achieved using full spectrum led plus far-red LED $\left(\mathrm{L}_{\max }=\right.$ $735 \mathrm{~nm}$; Philips, The Netherlands).

Chlorophyll (Chl) fluorescence parameters: The second functionally developed leaf from the top down was selected $15 \mathrm{~d}$ after the treatment and Chl fluorescence parameters were measured using a $P A M-2500$ chlorophyll fluorometer (Walz, Germany). After 30 min of full dark adaptation, leaves were irradiated with the measuring light to obtain the minimal fluorescence from dark-adapted leaves $\left(\mathrm{F}_{0}\right)$. Then, the maximal fluorescence from dark-adapted leaves $\left(\mathrm{F}_{\mathrm{m}}\right)$ was measured using a saturating flash. Subsequently, actinic light $\left[300 \mu \mathrm{mol}\left(\right.\right.$ photon) $\mathrm{m}^{-2} \mathrm{~s}^{-1}$ ] was turned on to measure the photosynthetic steady-state fluorescence $\left(\mathrm{F}_{\mathrm{s}}\right)$, and the saturated pulse light was turned on again to get the maximal fluorescence from light-adapted leaves $\left(F_{\mathrm{m}}{ }^{\prime}\right)$. Afterward, the actinic light was turned off and far-red light was immediately turned on to get the minimal fluorescence from light-adapted leaves $\left(\mathrm{F}_{0}{ }^{\prime}\right)$. Based on the index above, maximum quantum efficiency of PSII photochemistry $\left(\mathrm{F}_{\mathrm{v}} / \mathrm{F}_{\mathrm{m}}\right)$, PSII maximum efficiency $\left(\mathrm{F}_{\mathrm{v}}{ }^{\prime} / \mathrm{F}_{\mathrm{m}}{ }^{\prime}\right)$, actual electron transport operating efficiency $\left(\Phi_{\text {PSII }}\right)$, photochemical quenching $\left(\mathrm{q}_{\mathrm{P}}\right)$, nonphotochemical quenching (NPQ), antenna heat dissipation (D), reduced PSII photochemistry $(\mathrm{P})$, and excess energy in the reaction centre during the photochemical reaction (Ex) were calculated (Baker 2008).

Gas exchange parameters: After $15 \mathrm{~d}$ of treatments, a $L I-6400$ portable photosynthesis instrument $(\mathrm{Li}-\mathrm{COR}$, USA) was used to measure the net photosynthetic rate $\left(P_{\mathrm{N}}\right)$, stomatal conductance $\left(g_{\mathrm{s}}\right)$, intercellular $\mathrm{CO}_{2}$ concentration $\left(C_{\mathrm{i}}\right)$, and transpiration rate $(E)$ in the third functional leaf from the top. The parameters were determined between 9:00 and 11:00 h. In the assimilation chamber, ambient $\mathrm{CO}_{2}$ concentration was $400 \pm 10 \mathrm{ppm}$ and photosynthetic photon flux density (PPFD) was $1,000 \mu \mathrm{mol}$ $\mathrm{m}^{-2} \cdot \mathrm{s}^{-1}$. Quantification was repeated thrice.

Expression levels of a Rubisco gene: Total RNA was isolated from leaves using the E.Z.N.A. Plant RNA Kit (Omega Bio-tek, Doraville, GA, USA) according to the manufacturer's instructions. FastKing one-step method (Tiangen, Beijing, China) was then used to remove DNA contamination and perform reverse transcription. Subsequently, real-time PCR was conducted on a $C F X 96^{T M}$ real-time PCR cycler (Bio-Rad, Hercules, CA, USA). Then, the fluorescence real-time quantitative dye from the SYBR Premix Ex TaqTM II (Tli RNaseH Plus) kit (Takara, Japan) was used. Gene amplification primers, specific to the desired reaction design, were adopted from Primer Premier 5.0.0. RBCS (Rubisco small subunit). Primer sequences were: F: 5'-TTGAGACTGAGCACGGATTT-3' and R: 5'-GCTTGTGGGTATGCCTTT-3'. Tomato's actin was used as an internal reference. Actin's primer sequences were F: 5'-TGGTCGGAATGGGACAGAAG-3' and R: 5'-CTCAGTCAGGAGAACAGGGT-3'. The $2^{-\Delta \Delta C T}$ method was used to calculate the relative expression of genes (Livak and Schmittgen 2001). Quantification was repeated thrice.

Leaf proline content: After $15 \mathrm{~d}$ of treatment, we selected fully expanded leaves for measurement and measured their proline contents using the ninhydrin assay (Alves et al. 2020). Fresh leaves samples (0.5 g) were homogenized in 3\% sulphosalicylic acid and filtered. The mixture filtrate was added with $1 \mathrm{~mL}$ each of acid ninhydrin and glacial acetic acid and was placed in boiling water for $1 \mathrm{~h}$. Toluene $(4 \mathrm{~mL})$ was added to the mixture, and the absorbance was measured spectrophotometrically at $520 \mathrm{~nm}$. Quantification was repeated thrice.

Determination of tomato plant growth index: On the $15^{\text {th }} \mathrm{d}$ of the treatment, plants were harvested and washed. After absorbing water with absorbent paper, plant height, stem thickness, and fresh mass were measured. The whole plant was then dried at $105^{\circ} \mathrm{C}$ for $30 \mathrm{~min}$ and dried again at $60^{\circ} \mathrm{C}$ to a constant mass, after which the dry mass was determined.

Statistical analysis: SPSS data-processing software was used to calculate the variance of the experimental data and to test for significance $(p<0.05)$ of the differences between values. Data were given as mean \pm standard error. Origin 2018 (OriginLab, USA) was used to construct the graphs.

Table 1. Effects of red:far-red (R:FR) ratio on growth parameters and proline content in tomato seedlings under calcium nitrate stress. $\mathrm{CK}-0 \mathrm{mM} \mathrm{Ca}\left(\mathrm{NO}_{3}\right)_{2}+4.2 \mathrm{R}: \mathrm{FR} ; \mathrm{S}-160 \mathrm{mM} \mathrm{Ca}\left(\mathrm{NO}_{3}\right)_{2}+4.2 \mathrm{R}: \mathrm{FR} ; \mathrm{L} 1-0 \mathrm{mM} \mathrm{Ca}\left(\mathrm{NO}_{3}\right)_{2}+1.0 \mathrm{R}: \mathrm{FR} ; \mathrm{SL} 1-160 \mathrm{mM} \mathrm{Ca}\left(\mathrm{NO}_{3}\right)_{2}+$ 1.0 R:FR; L2 - 0 mM Ca( $\left(\mathrm{NO}_{3}\right)_{2}+0.7 \mathrm{R}: F R ; \mathrm{SL} 2-160 \mathrm{mM} \mathrm{Ca}\left(\mathrm{NO}_{3}\right)_{2}+0.7 \mathrm{R}: \mathrm{FR}$. Values represent means $\pm \mathrm{SE}, n=3$. Means denoted by the same letter did not differ significantly at $p<0.05$ according to Duncan's multiple range test. DM - dry mass; FM - fresh mass.

\begin{tabular}{|c|c|c|c|c|c|c|c|}
\hline Treatment & $\begin{array}{l}\text { Plant height } \\
{[\mathrm{cm}]}\end{array}$ & $\begin{array}{l}\text { Stem diameter } \\
{[\mathrm{mm}]}\end{array}$ & $\begin{array}{l}\text { FM [g] } \\
\text { Shoot }\end{array}$ & Root & $\begin{array}{l}\mathrm{DM}[\mathrm{g}] \\
\text { Shoot }\end{array}$ & Root & $\begin{array}{l}\text { Leaf proline content } \\
{\left[\mu \mathrm{g} \mathrm{g}^{-1}(\mathrm{FM})\right]}\end{array}$ \\
\hline $\mathrm{CK}$ & $26.87 \pm 0.19^{d}$ & $4.13 \pm 0.10^{\mathrm{b}}$ & $6.21 \pm 0.59^{\mathrm{d}}$ & $2.92 \pm 0.23^{b c}$ & $0.76 \pm 0.01^{\mathrm{c}}$ & $0.21 \pm 0.01^{\mathrm{bc}}$ & $26.93 \pm 2.03^{\mathrm{d}}$ \\
\hline $\mathrm{S}$ & $20.47 \pm 0.59^{\mathrm{e}}$ & $3.59 \pm 0.11^{\mathrm{c}}$ & $3.29 \pm 0.50^{\mathrm{e}}$ & $1.62 \pm 0.18^{d}$ & $0.49 \pm 0.04^{\mathrm{d}}$ & $0.15 \pm 0.01^{\mathrm{c}}$ & $153.04 \pm 30.57^{\mathrm{c}}$ \\
\hline L1 & $39.80 \pm 1.25^{\mathrm{b}}$ & $4.19 \pm 0.05^{\mathrm{b}}$ & $10.30 \pm 0.70^{\mathrm{b}}$ & $3.43 \pm 0.06^{\mathrm{ab}}$ & $1.03 \pm 0.03^{\mathrm{b}}$ & $0.28 \pm 0.01^{\mathrm{b}}$ & $27.90 \pm 1.20^{\mathrm{d}}$ \\
\hline SL1 & $29.23 \pm 0.88^{\mathrm{cd}}$ & $3.57 \pm 0.11^{\mathrm{c}}$ & $6.47 \pm 0.14^{\mathrm{d}}$ & $1.82 \pm 0.04^{\mathrm{d}}$ & $0.85 \pm 0.03^{c}$ & $0.18 \pm 0.01^{\mathrm{bc}}$ & $260.93 \pm 22.38^{b}$ \\
\hline L2 & $52.40 \pm 1.99^{\mathrm{a}}$ & $4.64 \pm 0.06^{\mathrm{a}}$ & $14.27 \pm 0.95^{\mathrm{a}}$ & $4.12 \pm 0.48^{\mathrm{a}}$ & $1.68 \pm 0.06^{\mathrm{a}}$ & $0.41 \pm 0.05^{\mathrm{a}}$ & $27.35 \pm 0.73^{\mathrm{d}}$ \\
\hline SL2 & $33.90 \pm 1.81^{\mathrm{c}}$ & $3.61 \pm 0.04^{\mathrm{c}}$ & $8.28 \pm 0.18^{c}$ & $2.15 \pm 0.25^{\mathrm{cd}}$ & $1.08 \pm 0.08^{\mathrm{b}}$ & $0.25 \pm 0.04^{\mathrm{bc}}$ & $415.87 \pm 20.16^{\mathrm{a}}$ \\
\hline
\end{tabular}




\section{Results}

Tomato plant growth index: Tomato seedlings grown under calcium nitrate stress (S) for $15 \mathrm{~d}$ had significantly lower plant height, stem diameter, and dry and fresh shoot mass than the control (CK) (Table 1). Treatments of lower R:FR ratio under calcium nitrate stress (SL1 and SL2) significantly reduced the indices mentioned above, except for the stem diameter. However, when low R:FR ratios treatments were applied without saline, higher plant heights, fresh mass, and dry mass were obtained when compared with $\mathrm{CK}$.

Leaf proline content: Applying calcium nitrate increased the proline content in seedlings' leaves (treatments S, SL1, and SL2) (Table 1). From Table 1, it is evident that a higher proline content was present in SL2 $(\mathrm{R}: \mathrm{FR}=0.7)$ than that in SL1 (R:FR = 1.0). However, when subjected to normal nutrient solutions, no significant difference between the $\mathrm{R}: F R$ ratio treatments was observed.
Chl fluorescence parameters: Calcium nitrate stress significantly reduced $\mathrm{F}_{\mathrm{v}}{ }^{\prime} / \mathrm{F}_{\mathrm{m}}{ }^{\prime}, \Phi_{\mathrm{PSII}}$, and $\mathrm{q}_{\mathrm{P}}$ of tomato leaves but increased NPQ (Table 2). However, $F_{v} / F_{m}$ of tomato leaves was not changed significantly (Table 2). With reduced R:FR ratios under stress conditions, the photosynthetic efficiency increased with an increase in $\mathrm{F}_{\mathrm{v}}{ }^{\prime} / \mathrm{F}_{\mathrm{m}}{ }^{\prime}, \Phi_{\mathrm{PSI}}, \mathrm{q}_{\mathrm{P}}$, and a decrease in NPQ (Table 2). Calcium nitrate stress also decreased PSII photochemistry $(\mathrm{P})$ and increased the antenna heat dissipation (D) (Fig. 1A,B). The results also showed that under stress conditions, low $F: F R$ ratios treatments increased the proportions of $P$ and $\mathrm{D}$, whereas it decreased the amount of excess energy at the reaction centre (Ex) (Fig. 1C). Low F:FR ratios treatments also led to a decrease in Chl fluorescence parameters while simultaneously increasing $\mathrm{P}$ levels during unstressed conditions.

Leaf photosynthetic characteristics: Under calcium nitrate stress, $P_{\mathrm{N}}, g_{\mathrm{s}}, E$, and $C_{\mathrm{i}}$ of tomato leaves significantly decreased when compared to CK. In contrast, $P_{\mathrm{N}}$ and $C_{\mathrm{i}}$

Table 2. Effects of different red:far-red (R:FR) ratios on chlorophyll fluorescence parameters of tomato seedlings under calcium nitrate stress. $\mathrm{F}_{\mathrm{v}} / \mathrm{F}_{\mathrm{m}}-$ maximum quantum efficiency of PSII photochemistry; $\mathrm{F}_{\mathrm{v}}{ }^{\prime} / \mathrm{F}_{\mathrm{m}}{ }^{\prime}-$ PSII maximum efficiency; $\Phi_{\text {PSII }}-$ actual photochemical efficiency of PSII; $q_{p}$ - photochemical quenching; NPQ - nonphotochemical quenching. The plants were subjected to the same treatments as in Table 1. Values represent means $\pm \mathrm{SE}, n=5$. Means denoted by the same letter did not differ significantly at $p<0.05$ according to Duncan's multiple range test.

\begin{tabular}{llllll}
\hline Treatment & $\mathrm{F}_{\mathrm{v}} / \mathrm{F}_{\mathrm{m}}$ & $\mathrm{F}_{\mathrm{v}}{ }^{\prime} / \mathrm{F}_{\mathrm{m}}{ }^{\prime}$ & $\Phi_{\text {PSII }}$ & $\mathrm{q}_{\mathrm{P}}$ & $\mathrm{NPQ}$ \\
\hline $\mathrm{CK}$ & $0.788 \pm 0.006^{\mathrm{a}}$ & $0.65 \pm 0.01^{\mathrm{bc}}$ & $0.47 \pm 0.02^{\mathrm{b}}$ & $0.72 \pm 0.02^{\mathrm{b}}$ & $0.56 \pm 0.03^{\mathrm{c}}$ \\
$\mathrm{S}$ & $0.787 \pm 0.004^{\mathrm{a}}$ & $0.55 \pm 0.01^{\mathrm{e}}$ & $0.26 \pm 0.01^{\mathrm{c}}$ & $0.46 \pm 0.01^{\mathrm{c}}$ & $0.90 \pm 0.03^{\mathrm{a}}$ \\
L1 & $0.793 \pm 0.002^{\mathrm{a}}$ & $0.65 \pm 0.01^{\mathrm{b}}$ & $0.53 \pm 0.02^{\mathrm{a}}$ & $0.82 \pm 0.02^{\mathrm{a}}$ & $0.59 \pm 0.04^{\mathrm{c}}$ \\
SL1 & $0.793 \pm 0.003^{\mathrm{a}}$ & $0.61 \pm 0.01^{\mathrm{d}}$ & $0.43 \pm 0.02^{\mathrm{b}}$ & $0.71 \pm 0.03^{\mathrm{b}}$ & $0.77 \pm 0.03^{\mathrm{b}}$ \\
L2 & $0.792 \pm 0.003^{\mathrm{a}}$ & $0.68 \pm 0.01^{\mathrm{a}}$ & $0.56 \pm 0.01^{\mathrm{a}}$ & $0.83 \pm 0.02^{\mathrm{a}}$ & $0.47 \pm 0.02^{\mathrm{d}}$ \\
SL2 & $0.799 \pm 0.004^{\mathrm{a}}$ & $0.63 \pm 0.01^{\mathrm{c}}$ & $0.46 \pm 0.01^{\mathrm{b}}$ & $0.73 \pm 0.02^{\mathrm{b}}$ & $0.73 \pm 0.02^{\mathrm{b}}$ \\
\hline
\end{tabular}
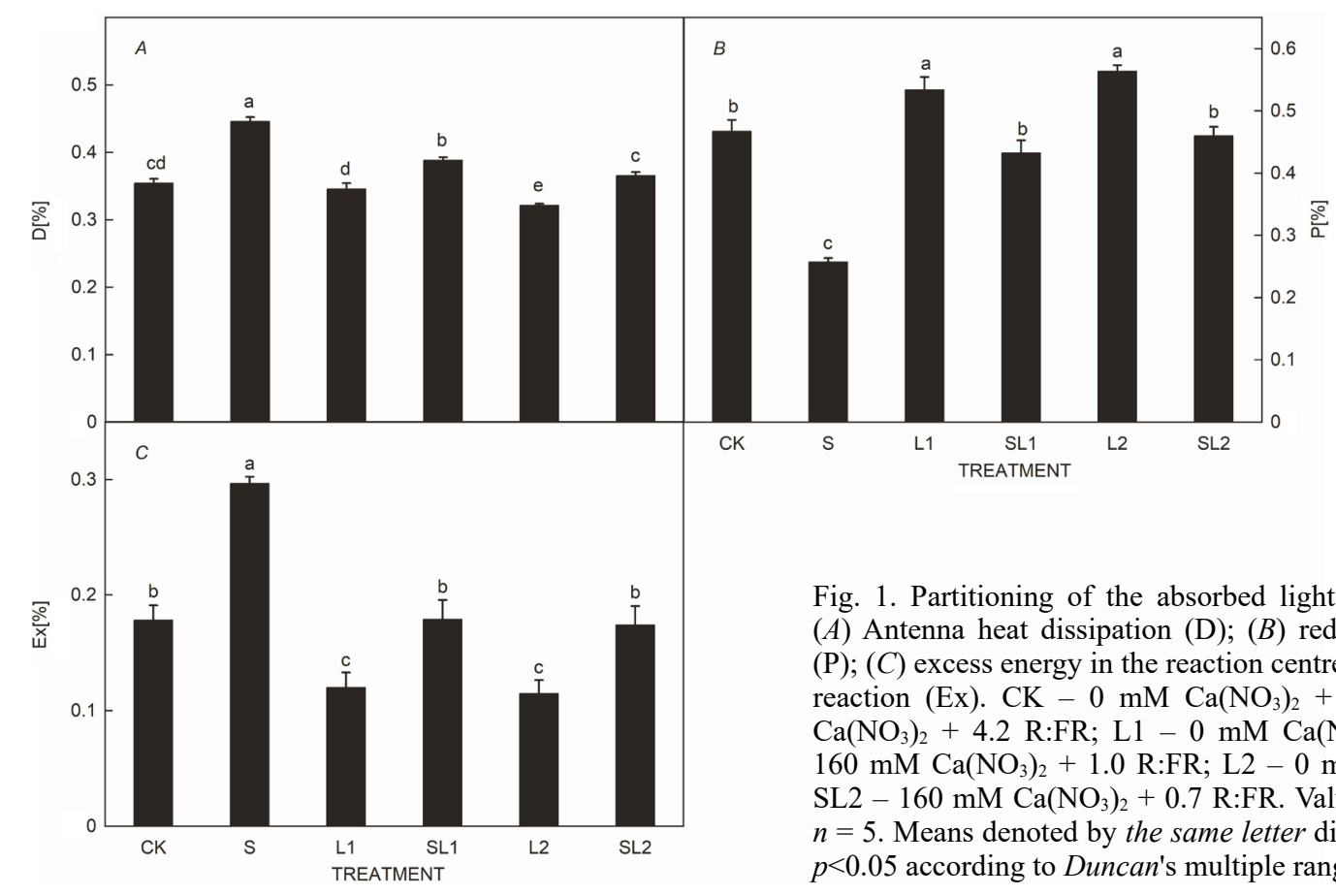

Fig. 1. Partitioning of the absorbed light energy in tomato leaves. (A) Antenna heat dissipation (D); $(B)$ reduced PSII photochemistry $(\mathrm{P}) ;(C)$ excess energy in the reaction centre during the photochemical reaction (Ex). CK - $0 \mathrm{mM} \mathrm{Ca}\left(\mathrm{NO}_{3}\right)_{2}+4.2 \mathrm{R}: \mathrm{FR} ; \mathrm{S}-160 \mathrm{mM}$ $\mathrm{Ca}\left(\mathrm{NO}_{3}\right)_{2}+4.2$ R:FR; L1 - $0 \mathrm{mM} \mathrm{Ca}\left(\mathrm{NO}_{3}\right)_{2}+1.0$ R:FR; SL1 $160 \mathrm{mM} \mathrm{Ca}\left(\mathrm{NO}_{3}\right)_{2}+1.0 \mathrm{R}: \mathrm{FR} ; \mathrm{L} 2-0 \mathrm{mM} \mathrm{Ca}\left(\mathrm{NO}_{3}\right)_{2}+0.7 \mathrm{R}: \mathrm{FR} ;$ $\mathrm{SL} 2-160 \mathrm{mM} \mathrm{Ca}\left(\mathrm{NO}_{3}\right)_{2}+0.7 \mathrm{R}: \mathrm{FR}$. Values represent means $\pm \mathrm{SE}$, $n=5$. Means denoted by the same letter did not differ significantly at $p<0.05$ according to Duncan's multiple range test. 
significantly increased under SL1 and SL2 treatments compared to S (Fig. 2). The results also showed that SL2 significantly increased $g_{\mathrm{s}}$ compared with $\mathrm{S}$. Moreover, both $\mathrm{L} 1$ and $\mathrm{L} 2$ increased $P_{\mathrm{N}}, g_{\mathrm{s}}, E$, and $C_{\mathrm{i}}$ of tomato leaves when compared with $\mathrm{CK}$.

Expression level of a Rubisco gene: Under calcium nitrate stress, the expression of $R B C S$ in leaves decreased significantly on the $1^{\text {st }}$ and $5^{\text {th }} \mathrm{d}$ after the treatments, respectively (Fig. 3). However, the RBCS gene expression increased significantly when low R:FR ratios were applied under calcium nitrate stress conditions. Moreover, a rise in $R B C S$ gene expression of leaves under L1 was observed on the $5^{\text {th }}$ day after treatment when compared with $C K$.

\section{Discussion}

Both growth and development of the tomato seedlings were slowed down by salt stress. However, these seedlings coped with the stress in various ways. By increasing the

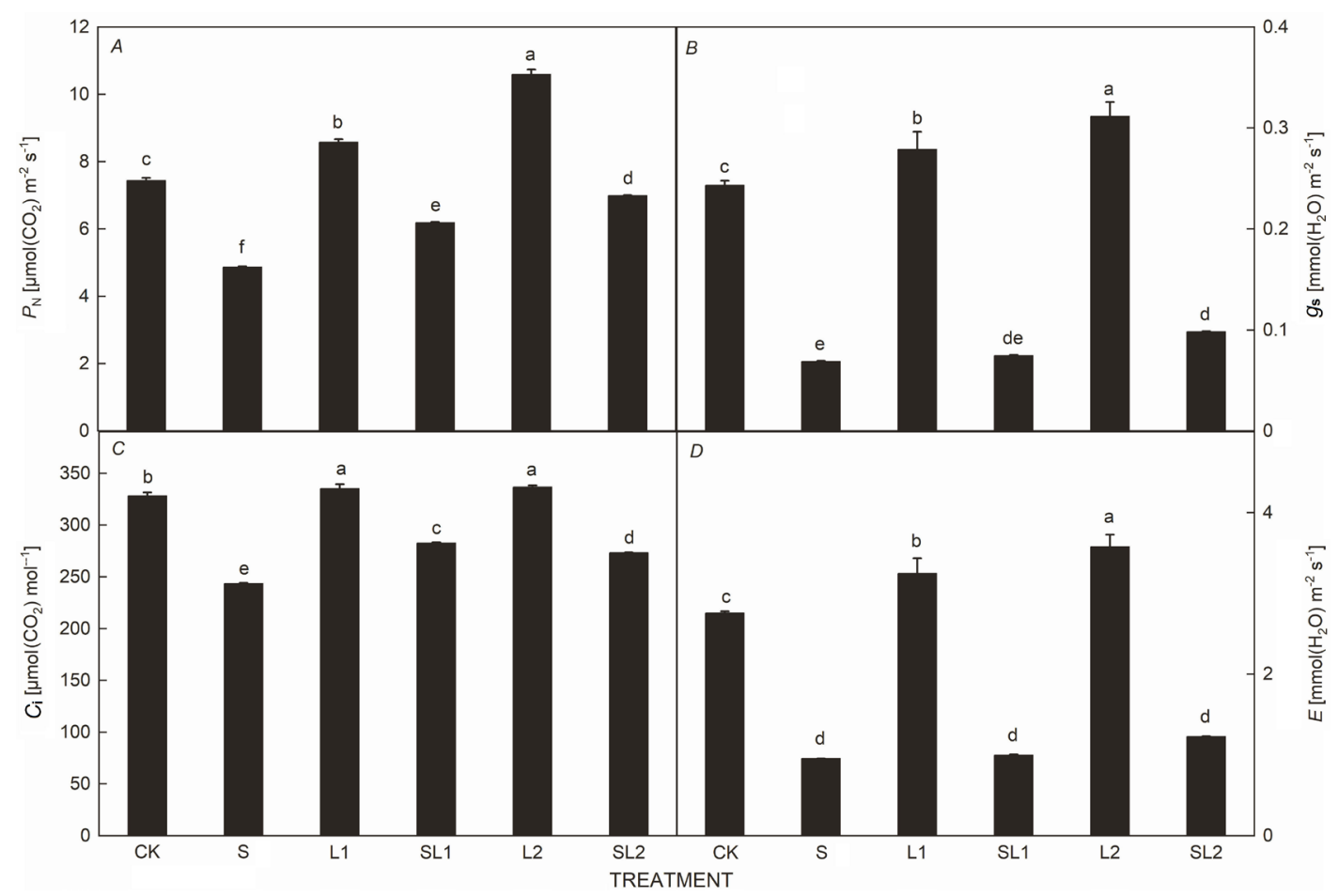

Fig. 2. Effects of different red:far-red (R:FR) ratios on gas-exchange parameters of tomato seedlings' leaves under calcium nitrate stress. $(A)$ Net photosynthetic rate $\left(P_{\mathrm{N}}\right) ;(B)$ stomatal conductance $\left(g_{\mathrm{s}}\right) ;(C)$ intercellular $\mathrm{CO}_{2}$ concentration $\left(C_{\mathrm{i}}\right) ;(D)$ transpiration rate $(E)$. The plants were subjected to the same treatments as in Fig. 1. Values represent means $\pm \mathrm{SE}, n=4$. Means denoted by the same letter did not differ significantly at $p<0.05$ according to Duncan's multiple range test.

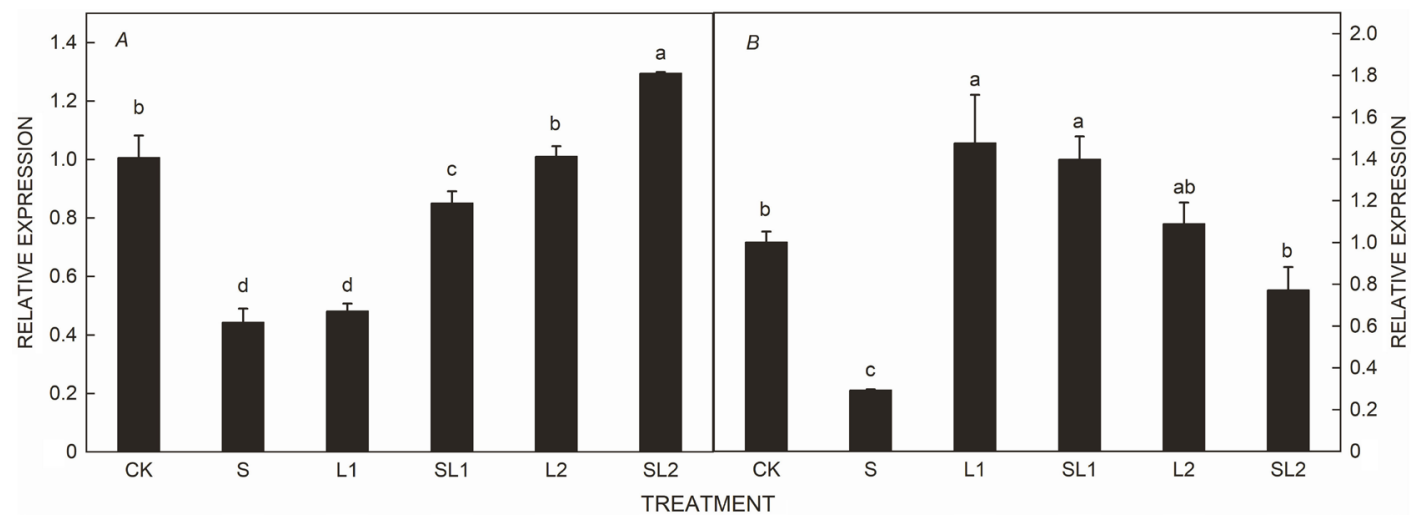

Fig. 3. Effects of different red:far-red (R:FR) ratios on the expression level of the Rubisco small subunit $(R B C S)$ gene of tomato under calcium nitrate stress. Expression level of $R B C S$ on the $1^{\text {st }}(A)$ and $5^{\text {th }}(B)$ day of stress treatment. The plants were subjected to the same treatments as in Fig. 1. Values represent means $\pm \mathrm{SE}, n=3$. Means denoted by the same letter did not differ significantly at $p<0.05$ according to Duncan's multiple range test. 
R:FR ratio, the distance between stem nodes, plant height, and leaf area decreased. However, when the R:FR ratio is low, the distance between stem nodes becomes larger and a plant becomes elongated. In this scenario, more photosynthates are distributed in the stem ( $\mathrm{Li}$ and Kubota 2009). In this study, low R:FR ratio treatment increased the tomato seedling height under stress. A low R:FR ratio treatment also significantly increased both fresh and dry masses of shoots under calcium nitrate stress. Additionally, the stem diameter of the tomato plant increased under a low R:FR ratio treatment without salt stress. This result was consistent with that reported by Wang et al. (2021) but inconsistent with that of Cao et al. (2018). Reduced R:FR ratios under calcium nitrate stress promoted the growth of the aboveground part.

Studies have shown that plant photosynthetic rate can be significantly reduced under high salt stress (Liang et al. 2021, Liao and Zhang 2021). Results of the present study support this point. Under calcium nitrate stress, $P_{\mathrm{N}}, g_{\mathrm{s}}$, and $C_{\mathrm{i}}$ decreased simultaneously. However, under low $\mathrm{R}: \mathrm{FR}$ ratios treatments, the photosynthetic gas-exchange parameters of both salt-stressed and nonstressed plants increased. Yang et al. (2020) reported a low R:FR light treatment increased the net photosynthetic rate of soybean leaves. Another report by Wang et al. (2021) showed that a low R:FR light treatment enhanced the net photosynthetic rate of tomato leaves under $\mathrm{NaCl}$ stress. In the present study, low R:FR ratios treatments alleviated the decrease of photosynthetic rate under calcium nitrate stress, which promoted tomato growth.

Using Chl fluorescence parameters, researchers can quickly, sensitively, and nondestructively determine the status of the PSII reaction centres (Li et al. 2004). Under stress conditions, $\mathrm{F}_{\mathrm{v}}{ }^{\prime} / \mathrm{F}_{\mathrm{m}}{ }^{\prime}, \Phi_{\mathrm{PSII}}$, and $\mathrm{q}_{\mathrm{P}}$ in the leaves decreased, indicating that electron transport in PSII was blocked under salt stress. Moreover, the Chl fluorescence parameters of the tomato seedlings were altered when the low R:FR ratio was applied. Lower R:FR ratios treatments could improve $\mathrm{F}_{\mathrm{v}}{ }^{\prime} / \mathrm{F}_{\mathrm{m}}{ }^{\prime}, \Phi_{\mathrm{PSII}}, \mathrm{q}_{\mathrm{P}}$, and reduce NPQ under stress conditions. These results indicated that lower R:FR ratios treatments can decrease salt-induced inhibition of the PSII electron transport and improve salt tolerance of tomato seedlings, which is consistent with the results of Shu et al. (2013) and Wang et al. (2018). Similarly, Yang et al. (2020) also reported that under the same illumination conditions, a low R:FR ratio treatment significantly improved the quantum yield of PSII, which was consistent with the results of this experiment.

In our study, low R:FR ratios treatments and calcium nitrate stress affected light energy allocation in chloroplasts and we used fluorescence parameters to divide the light energy absorbed by plant leaves into three parts (DemmigAdams et al. 1996): the first is the antenna heat dissipation energy part (D), the second is the excess energy in the reaction centre during the photochemical reaction part (Ex), and the third is the PSII's photochemistry part (P). The study showed that under calcium nitrate stress, $\mathrm{P}$ of tomato leaves decreased significantly, D increased, and Ex increased (Fig. 1). These results reflected a kind of plant's ability; increasing the excitation energy antenna heat dissipation can reduce the excessive reduction of PSII and electron transport chain. The change is related to the plant lutein cycle, which is the protective mechanism of plants against the destruction of the photosynthetic machinery. Meanwhile, the increase of Ex led to the increase of excitation pressure of PSII, which led to the temporary accumulation of ${ }^{1} \mathrm{Chl}$ and might transfer energy to $\mathrm{O}_{2}$, forming the extremely destructive singlet oxygen (Asada 1999, Zhou et al. 2004). Therefore, under calcium nitrate stress, whether the influence of low R:FR ratios treatments on PSII reaction center was related to the lutein cycle, the production and existence of singlet oxygen, and the change of reactive oxygen species remained to be further studied.

Under salt stress conditions, water potential decreased due to excessive ion concentration in the medium, thereby making it difficult for the plants to absorb water (Hasegawa et al. 2000). These plants, therefore, showed physiological drought. Many plants accumulated proline under salt stress conditions as a nontoxic protective osmoticum because it did not participate in the reactions associated with enzyme activity change, even at high concentrations (Parida and Das 2005). Proline plays an important role in stabilizing subcellular structures and scavenging free radicals (Gururani et al. 2016). In our study, we found that under low R:FR ratios treatments, proline content in tomato leaves increased under calcium nitrate stress. The treatment with the R:FR ratio of 1.0 and 0.7 significantly increased proline content in tomato leaves under calcium nitrate stress. Low R:FR ratios treatments increased the proline contents under calcium nitrate stress, thereby increasing the salt tolerance of tomato plants due to its osmotic protection and proposed participation in freeradical scavenging.

The RBCS gene encodes for the small subunit of Rubisco, a key enzyme of the dark reaction of photosynthesis. In the Calvin cycle, Rubisco is a rate-limiting enzyme for $\mathrm{CO}_{2}$ assimilation and its activity and gene expression can determine the ability of plants to assimilate $\mathrm{CO}_{2}$ in the dark reaction of photosynthesis (Karim et al. 2003). Abiotic stress affects the expression and catalytic activity of this Rubisco enzyme as well as the photosynthetic rate of plants. Results of the present study showed that the expression level of $R B C S$ in tomato seedlings' leaves decreased under calcium nitrate stress. The expression levels of RBCS in SL1 and SL2 significantly increased compared to $\mathrm{S}$ in the study. These results indicated that low $\mathrm{R}: \mathrm{FR}$ ratios treatments reduced the inhibition of calcium nitrate stress during the dark photosynthesis stage, which improved the synthetic carbon uptake.

Cao et al. (2018) found that plants under low R: FR ratios treatments were salt tolerant along with the fact that many indicator traits were improved, such as increased ROS scavenging activity (CAT, POD, and SOD) and decreased ROS content (superoxide anion and hydrogen peroxide). However, in tomato phyB 1 mutants, salt tolerance induced by low R:FR ratios treatments disappeared, indicating that low R:FR ratios treatments improved salt tolerance and phyB 1 played a very important role in this process. In our study, the upregulation of the $R B C S$ gene in tomato leaves was observed under salt stress and low R:FR ratio 
conditions. To explain this result, further research is needed on the effect of R:FR ratios and the phytochrome system on the photosynthetic pathway.

Our study also showed that low R:FR ratios treatments significantly affected the salinity tolerance of tomato seedlings. Under stress conditions, tomato plant height, fresh and dry mass, $\Phi_{\mathrm{PSII}}$, and proline were significantly altered under low R:FR treatments. These results indicated that low R:FR ratios treatments improved tomato salinity stress tolerance and played an important role in this process.

Conclusions: Low R:FR ratios treatments increased the values of $\mathrm{F}_{\mathrm{v}}{ }^{\prime} / \mathrm{F}_{\mathrm{m}}{ }^{\prime}, \Phi_{\mathrm{PSII}}$, and $\mathrm{q}_{\mathrm{P}}$ in tomato seedlings under calcium nitrate stress, lowered the value of NPQ, and increased the quantum yield of PSII. Under calcium nitrate stress, low R:FR ratios treatments had a significant effect on both the quantum yield of PSII and the expression of the Rubisco gene, which led to increased photosynthetic rates. Effects of promoting tomato growth and improving the quantum yield of PSII were most favourable when the R:FR ratio was set to 0.7 in this experiment. The findings also revealed that calcium nitrate stress caused peroxidative damage to tomatoes. Furthermore, reduced $\mathrm{R}: \mathrm{FR}$ ratios led to an increase in the proline content in the tomato seedlings, in addition to improved osmotic adjustments and salt tolerance.

\section{References}

Ahres M., Gierczik K., Boldizsár Á. et al.: Temperature and light-quality-dependent regulation of freezing tolerance in barley. - Plants 9: 83, 2020.

Alves L.R., Prado E.R., Oliveira R.D. et al.: Mechanisms of cadmium-stress avoidance by selenium in tomato plants. Ecotoxicology 29: 594-606, 2020.

Arico D., Legris M., Castro L. et al.: Neighbour signals perceived by phytochrome B increase thermotolerance in Arabidopsis. Plant Cell Environ. 42: 2554-2566, 2019.

Asada K.: The water-water cycle in chloroplasts: Scavenging of active oxygens and dissipation of excess photons. - Annu. Rev. Plant Phys. 50: 601-639, 1999.

Baker N.R.: Chlorophyll fluorescence: a probe of photosynthesis in vivo. - Annu. Rev. Plant Biol. 59: 89-113, 2008.

Bergougnoux V.: The history of tomato: From domestication to biopharming. - Biotechnol. Adv. 32: 170-189, 2014.

Boggs J.Z., Loewy K., Bibee K., Heschel M.S.: Phytochromes influence stomatal conductance plasticity in Arabidopsis thaliana. - Plant Growth Regul. 60: 77-81, 2010.

Cao K., Yu J., Xu D. et al.: Exposure to lower red to far-red light ratios improve tomato tolerance to salt stress. - BMC Plant Biol. 18: 92, 2018.

Craig D.S., Runkle E.S.: A moderate to high red to far-red light ratio from light-emitting diodes controls flowering of shortday plants. - J. Am. Soc. Hortic. Sci. 138: 167-172, 2013.

Demmig-Adams B., Adams III W.W., Barker D.H. et al.: Using chlorophyll fluorescence to assess the fraction of absorbed light allocated to thermal dissipation of excess excitation. Physiol. Plantarum 98: 253-264, 1996.

Fahad S., Hussain S., Matloob A. et al.: Phytohormones and plant responses to salinity stress: a review. - Plant Growth Regul. 75: 391-404, 2015.

Franklin K.A., Quail P.H.: Phytochrome functions in Arabidopsis development. - J. Exp. Bot. 61: 11-24, 2010.

Gururani M.A., Ganesan M., Song I.-J. et al.: Transgenic turfgrasses expressing hyperactive Ser599Ala phytochrome A mutant exhibit abiotic stress tolerance. - J. Plant Growth Regul. 35: 11-21, 2016.

Hasegawa P.M., Bressan R.A., Zhu J.K., Bohnert H.J.: Plant cellular and molecular responses to high salinity. - Annu. Rev. Plant Phys. 51: 463-499, 2000.

Hendricks S.B., Borthwick H.A.: The function of phytochrome in regulation of plant growth. - P. Natl. Acad. Sci. USA 58: 2125-2130, 1967.

Hertel C., Leuchner M., Menzel A.: Vertical variability of spectral ratios in a mature mixed forest stand. - Agr. Forest Meteorol. 151: 1096-1105, 2011.

Indorf M., Cordero J., Neuhaus G., Rodríguez-Franco M.: Salt tolerance (STO), a stress-related protein, has a major role in light signalling. - Plant J. 51: 563-574, 2007.

Karim A., Fukamachi H., Hidaka T.: Photosynthetic performance of Vigna radiata L. leaves developed at different temperature and irradiance leaves. - Plant Sci. 164: 451-458, 2003.

Kim H.-J., Kim Y.-K., Park J.Y., Kim J.: Light signalling mediated by phytochrome plays an important role in coldinduced gene expression through the C-repeat/dehydration responsive element (C/DRE) in Arabidopsis thaliana. - Plant J. 29: 693-704, 2002.

Lakshmi A., Ramanjulu S., Veeranjaneyulu K., Sudhakar C.: Effect of $\mathrm{NaCl}$ on photosynthesis parameters in two cultivars of mulberry. - Photosynthetica 32: 285-289, 1996.

Li J., Li G., Wang H., Deng X.W.: Phytochrome signaling mechanisms. - The Arabidopsis Book 9: e0148, 2011.

Li Q., Kubota C.: Effects of supplemental light quality on growth and phytochemicals of baby leaf lettuce. - Environ. Exp. Bot. 67: 59-64, 2009.

Li X.G., Wang X.M., Meng Q.W., Zou Q.: Factors limiting photosynthetic recovery in sweet pepper leaves after shortterm chilling stress under low irradiance. - Photosynthetica 42: 257-262, 2004.

Liang B.B., Wang W.J., Fan X.X. et al.: Arbuscular mycorrhizal fungi can ameliorate salt stress in Elaeagnus angustifolia by improving leaf photosynthetic function and ultrastructure. Plant Biol. 23: 232-241, 2021.

Liao R., Zhang L.: Physiological response of Solanum nigrum to salt stress. - E3S Web Conf. 233: 01140, 2021.

Livak K.J., Schmittgen T.D.: Analysis of relative gene expression data using real-time quantitative PCR and the $2^{-\triangle \Delta C T}$ method. - Methods 25: 402-408, 2001.

Martínez-García J.F., Gallemí M., Molina-Contreras M.J. et al.: The shade avoidance syndrome in Arabidopsis: the antagonistic role of phytochrome A and B differentiates vegetation proximity and canopy shade. - PLoS ONE 9: e109275, 2014.

Misra A.N., Sahu S.M., Misra M. et al.: Sodium chloride induced changes in leaf growth, and pigment and protein contents in two rice cultivars. - Biol. Plantarum 39: 257-262, 1997.

Ors S., Ekinci M., Yildirim E. et al.: Interactive effects of salinity and drought stress on photosynthetic characteristics and physiology of tomato (Lycopersiconesculentum L.) seedlings.S. Afr. J. Bot. 137: 335-339, 2021.

Parida A.K., Das A.B.: Salt tolerance and salinity effects on plants: a review. - Ecotox. Environ. Safe. 60: 324-349, 2005.

Possart A., Xu T., Paik I. et al.: Characterization of phytochrome interacting factors from the moss Physcomitrella patens illustrates conservation of phytochrome signaling modules in land plants. - Plant Cell 29: 310-330, 2017.

Quail P.H.: Phytochrome photosensory signaling networks. Nat. Rev. Mol. Cell Biol. 3: 85-93, 2002.

Rozema J., Flowers T.: Crop for a salinized world. - Science 322: 
1478-1480, 2008.

Shu S., Yuan L.Y., Guo S.R. et al.: Effects of exogenous spermine on chlorophyll fluorescence, antioxidant system and ultrastructure of chloroplasts in Cucumis sativus L. under salt stress. - Plant Physiol. Bioch. 63: 209-216, 2013.

Wang F., Wu N., Zhang L. et al.: Light signaling-dependent regulation of photoinhibition and photoprotection in tomato. Plant Physiol. 176: 1311-1326, 2018.

Wang H., Jiang Y.P., Yu H.J. et al.: Light quality affects incidence of powdery mildew, expression of defence-related genes and associated metabolism in cucumber plants. - Eur. J. Plant Pathol. 127: 125-135, 2010.

Wang Y.L., Bian Z.H., Pan T.H. et al.: Improvement of tomato salt tolerance by the regulation of photosynthetic performance and antioxidant enzyme capacity under a low red to far-red light ratio. - Plant Physiol. Bioch. 167: 806-815, 2021.
Yang F., Liu Q., Cheng Y. et al.: Low red/far-red ratio as a signal promotes carbon assimilation of soybean seedlings by increasing the photosynthetic capacity. - BMC Plant Biol. 20: 148,2020

Yang Y.X., Wang M.M., Yin Y.L. et al.: RNA-seq analysis reveals the role of red light in resistance against Pseudomonas syringae pv. tomato DC3000 in tomato plants. - BMC Genomics 16: 120, 2015.

Yuan L., Shu S., Sun J. et al.: Effects of 24-epi-brassinolide on the photosynthetic characteristics, antioxidant system, and chloroplast ultrastructure in Cucumis sativus L. under $\mathrm{Ca}\left(\mathrm{NO}_{3}\right)_{2}$ stress. - Photosynth. Res. 112: 205-214, 2012.

Zhou Y.H., Huang L.F., Yu J.Q.: [Effects of sustained chilling and low light on gas exchange, chlorophyll fluorescence quenching and absorbed light allocation in cucumber leaves.] Physiol. Mol. Biol. Pla. 30: 153-160, 2004. [In Chinese]

(C) The authors. This is an open access article distributed under the terms of the Creative Commons BY-NC-ND Licence. 